\title{
Gambaran Kejadian Dermatitis Kontak Akibat Kerja pada Petugas Cleaning Service di RSUP Prof. Dr. R. D. Kandou Manado
}

\author{
${ }^{1}$ Ristya M. Paendong \\ ${ }^{2}$ Herry Pandaleke \\ ${ }^{2}$ Ferra Mawu
}

\author{
${ }^{1}$ Program Studi Pendidikan Dokter Fakultas Kedokteran Universitas Sam Ratulangi Manado \\ ${ }^{2}$ Bagian Ilmu Kesehatan Kulit dan Kelamin Fakultas Kedokteran \\ Universitas Sam Ratulangi Manado \\ E-mail: ristyampaendong@gmail.com
}

\begin{abstract}
Work-related diseases that cause skin disorders are called occupational skin diseases inter alia contact dermatitis and urticaria. Work-related contact dermatitis reaches $20 \%$ of all occupational diseases; $80 \%$ of them occur in hands. Occupational contact dermatitis can be experienced by all workers such as cleaning service workers because they are often exposed to irritants and allergen substances in their work places due to unavailable personal protective equipment. This study was aimed to obtain the overview of occupational contact dermatitis incidence among cleaning services of Prof. Dr. R. D. Kandou Hospital Manado. This was a descriptive study with a cross sectional design. Respondents of this study involved 135 cleaning service workers obtained by using total sampling method. The results showed that 28 of 135 respondents $(20,7 \%)$ were suffered from occupational contact dermatitis. Conclusion: Occupational contact dermatitis was found in around $20 \%$ of the cleaning service workers at Prof. Dr. R. D. Kandou Hospital Manado.
\end{abstract}

Keywords: occupational contact dermatitis, cleaning service

\begin{abstract}
Abstrak: Penyakit akibat kerja yang menyebabkan kelainan pada kulit disebut penyakit kulit akibat kerja yang dapat berupa dermatitis kontak dan urtikaria. Dermatitis kontak akibat kerja (DKAK) mencapai 20\% dari seluruh penyakit akibat kerja dan 80\% terjadi di tangan. Dermatitis kontak akibat kerja dapat terjadi pada semua pekerja, diantaranya petugas cleaning service akibat sering terpapar bahan iritan dan alergen di tempat kerja tanpa penggunaan alat pelindung diri yang memadai dan tingkat kebersihan diri yang buruk. Penelitian ini bertujuan untuk mengetahui gambaran kejadian DKAK pada petugas cleaning service di RSUP Prof. Dr. R. D. Kandou Manado. Jenis penelitian ini ialah deskriptif dengan desain potong lintang. Jumlah responden penelitian sebanyak 135 orang diperoleh dengan teknik total sampling. Hasil penelitian menujukkan bahwa 28 dari 135 responden $(20,7 \%)$ mengalami dermatitis kontak akibat kerja. Simpulan: Dermatitis kontak akibat kerja ditemukan pada sekitar $20 \%$ petugas cleaning service RSUP Prof. Dr. R. D. Kandou Manado.
\end{abstract}

Kata kunci: dermatitis kontak akibat kerja, cleaning service

Masalah kesehatan dapat terjadi pada pekerja akibat proses pekerjaan, lingkungan perkerjaan serta perilaku kesehatan pekerja. Bukan hanya penyakit menular dan tidak menular tetapi juga penyakit akibat kerja. Penyakit akibat kerja adalah penyakit yang disebabkan oleh pekerjaan dan/atau ling- kungan kerja. ${ }^{1}$

Penyakit akibat kerja yang menyebabkan kelainan pada kulit disebut dengan penyakit kulit akibat kerja. Penyakit kulit akibat kerja dapat berupa dermatitis kontak dan urtikaria. Dermatitis kontak akibat kerja (DKAK) mencapai 20\% dari 
seluruh penyakit akibat kerja dan $80 \%$ terjadi di tangan. Meskipun kejadian DKAK secara global mengalami penurun-an, namun masih banyak kasus yang terjadi secara lokal yang tidak dilaporkan atau tidak mencari pengobatan sehingga tidak diterapi. ${ }^{2,3}$

Dermatitis kontak ialah dermatitis yang disebabkan oleh bahan atau substansi yang menempel pada kulit. Dikenal dua jenis dermatitis kontak yaitu dermatitis kontak iritan (DKI) dan dermatitis kontak alergika (DKA); keduanya dapat bersifat akut maupun kronis. Dermatitis kontak iritan merupakan reaksi peradangan kulit nonimunologik dimana kerusakan kulit terjadi langsung tanpa didahului proses pengenalan atau sensitisasi. Sebaliknya, DKA terjadi pada seseorang yang telah mengalami sensitisasi terhadap suatu bahan penyebab atau alergen. ${ }^{3}$

Dermatitis kontak akibat kerja dapat terjadi pada pekerja salon, pekerja bahan logam, pekerja industri makanan, petugas kebersihan, dan petugas kesehatan akibat sering terpapar bahan-bahan iritan dan alergen di tempat kerja tanpa penggunaan alat pelindung diri (APD) yang memadai dan tingkat kebersihan diri yang buruk. ${ }^{4}$ Dermatitis kontak akibat kerja yang paling sering ditemukan ialah jenis DKI. Bentuk DKI mencapai 60-80\% sedangkan DKA sekitar 20-40\%.5,6

Berdasarkan studi retrospektif yang dilakukan oleh Safe Work Australia antara 1 Januari 1993 sampai 31 Desember 2010 terdapat $2177(75,1 \%)$ pasien dengan diagnosis penyakit kulit akibat kerja; 958 (44\%) diantaranya ialah DKI dan 712 $(32,7 \%)$ ialah DKA. ${ }^{7}$ Di Indonesia, menurut Perhimpunan Dokter Spesialis Kulit dan Kelamin Indonesia sekitar 90\% penyakit kulit akibat kerja merupakan dermatitis kontak, baik DKI maupun DKA. ${ }^{8}$

Petugas kebersihan atau cleaning service adalah salah satu kelompok pekerja yang sering mengalami DKAK. Keadaan ini terutama akibat kombinasi pekerjaan basah dan terpapar dengan agen pembersih dalam frekuensi yang cukup tinggi. Satu studi di UK menemukan kejadian dermatitis sebanyak $28 \%$ pada petugas kebersihan versus $18 \%$ pada populasi umum., ${ }^{4,9}$ Penelitian yang dilakukan oleh Douwes et al. ${ }^{10}$ di New Zealand mendapatkan DKAK sebanyak $14,8 \%$ dalam tiga bulan terakhir dan $9,4 \%$ sebelum tiga bulan terakhir pada 418 petugas kebersihan dari berbagai tempat kerja yang salah satunya ialah rumah sakit. Penelitian yang dilakukan oleh Saftarina et al. ${ }^{11}$ terhadap petugas cleaning service di Rumah Sakit Umum Abdoel Moeloek mendapatkan 47 dari total 102 petugas mengalami DKAK.

Data dermatitis kontak di RSUP Prof. Dr. R. D. Kandou Manado berdasarkan kunjungan pasien di Poliklinik Kulit dan Kelamin sudah tercatat di bagian rekam medik, namun belum ada data khusus DKAK terutama yang terjadi pada pekerja di lingkungan rumah sakit khususnya pada petugas cleaning service.

Dermatitis kontak akibat kerja masih banyak dijumpai antara lain pada petugas cleaning service. Data kejadian DKAK penting untuk diketahui karena masih menjadi masalah kesehatan masyarakat termasuk di Indonesia akibat sifatnya yang kronik dan berdampak sosial ekonomi sehingga memengaruhi kualitas kerja dan kualitas hidup. ${ }^{6,9,12}$

\section{METODE PENELITIAN}

Penelitian ini dilaksanakan di RSUP Prof. Dr. R. D. Kandou Manado pada bulan September-November 2017. Jenis penelitian ialah deskriptif dengan desain potong lintang. Populasi penelitian ialah seluruh petugas cleaning service yang berjumlah 147 orang. Pengambilan sampel menggunakan metode total sampling. Data dikumpulkan dengan melakukan tatap muka dan wawancara langsung serta melakukan pengamatan penggunaan APD berupa sarung tangan. Diagnosis ditegakkan di bawah supervisi dokter dan dokter spesialis di Poliklinik Kulit dan Kelamin RSUP Prof. Dr. R. D. Kandou Manado. Analisis data dilakukan dengan mengguna-kan program Microsoft Excel dan SPSS 17.

Penelitian ini dilakukan setelah mendapat persetujuan etik dari Komisi Etik 
Penelitian Kesehatan RSUP Prof. Dr. R. D. Kandou Manado.

\section{HASIL PENELITIAN}

Responden penelitian ini berjumlah 135 petugas cleaning service yang bersedia dan menandatangani informed consent.

\section{Karakterisktik responden}

Tabel 1 menunjukkan karakteristik responden berdasarkan jenis kelamin. Sebagian besar responden berjenis kelamin perempuan yaitu sebanyak 90 responden $(66,7 \%)$ sedangkan yang berjenis kelamin laki-laki sebanyak 45 responden $(33,3 \%)$.

Tabel 1. Distribusi karakteristik responden berdasarkan jenis kelamin

\begin{tabular}{ccc}
\hline Jenis kelamin & Frekuensi & $\mathbf{( \% )}$ \\
\hline Laki-laki & 45 & 33,3 \\
Perempuan & 90 & 66,7 \\
Total & 135 & 100 \\
\hline
\end{tabular}

Tabel 2 menunjukkan karakteristik responden berdasarkan usia. Responden paling banyak berusia $36-45$ tahun $(31,1 \%)$, dan paling sedikit berusia $>65$ tahun $(0,7 \%)$. Rerata usia responden ialah 41,55 tahun dengan usia minimum 17 tahun dan maksimum 69 tahun.

Tabel 2. Distribusi responden berdasarkan usia

\begin{tabular}{ccc}
\hline Usia (tahun) & Frekuensi & $\mathbf{( \% )}$ \\
\hline $17-25$ & 14 & 10,4 \\
$26-35$ & 25 & 18,5 \\
$36-45$ & 42 & 31,1 \\
$46-55$ & 39 & 28,9 \\
$56-65$ & 14 & 10,4 \\
$>65$ & 1 & 0,7 \\
Total & 135 & 100 \\
\hline
\end{tabular}

Tabel 3 menunjukkan karakteristik responden berdasarkan pendidikan terakhir. Jenjang pendidikan SMP yang terbanyak $(39,3 \%)$, diikuti jenjang pendidikan SMA $(34,8 \%)$, dan yang paling sedikit yaitu jenjang pendidikan SD $(25,9 \%)$.

Tabel 4 menunjukkan karateristik responden berdasarkan masa kerja. Yang terbanyak yaitu masa kerja 1-5 tahun
$(45,2 \%)$, dan yang paling sedikit masa kerja $>20$ tahun $(4,4 \%)$. Rerata masa kerja responden yaitu 6,9 tahun dengan masa kerja minimum 1 bulan dan maksimum 30 tahun.

Tabel 3. Distribusi karakteristik responden berdasarkan pendidikan

\begin{tabular}{ccc}
\hline $\begin{array}{c}\text { Pendidikan } \\
\text { terakhir }\end{array}$ & Frekuensi & $\mathbf{( \% )}$ \\
\hline SD & 35 & 25,9 \\
SMP & 53 & 39,3 \\
SMA & 47 & 34,8 \\
Total & 135 & 100 \\
\hline
\end{tabular}

Tabel 4. Distribusi karakteristik responden berdasarkan masa kerja

\begin{tabular}{ccc}
\hline $\begin{array}{c}\text { Masa kerja } \\
\text { (tahun) }\end{array}$ & Frekuensi & $\mathbf{( \% )}$ \\
\hline$<1$ & 19 & 14,1 \\
$1-5$ & 61 & 45,2 \\
$6-10$ & 28 & 20,7 \\
$11-15$ & 11 & 8,1 \\
$16-20$ & 10 & 7,4 \\
$>20$ & 6 & 4,4 \\
Total & 135 & 100 \\
\hline
\end{tabular}

Tabel 5 menunjukkan distribusi karakteristik responden berdasarkan penggunaan APD yaitu sarung tangan. Sebanyak 69 responden $(51,1 \%)$ menggunakan APD, dan sebanyak 66 responden $(48,9 \%)$ tidak menggunakan APD.

Tabel 5. Distribusi karakteristik responden berdasarkan penggunaan APD

\begin{tabular}{ccc}
\hline Penggunaan APD & Frekuensi & $\mathbf{( \% )}$ \\
\hline Menggunakan & 69 & 51,1 \\
$\quad$ Tidak & 66 & 48,9 \\
Menggunakan & & \\
Total & 135 & 100 \\
\hline
\end{tabular}

\section{Kejadian dermatitis kontak akibat kerja}

Tabel 6 menunjukkan responden yang mengalami DKAK sebanyak 28 responden $(20,7 \%)$, dan yang tidak mengalami DKAK yaitu 107 responden $(79,3 \%)$. 
Tabel 6. Distribusi kejadian DKAK pada petugas cleaning service

\begin{tabular}{ccc}
\hline Kejadian & Frekuensi & $\mathbf{( \% )}$ \\
\hline DKAK & 28 & 20,7 \\
Tidak DKAK & 107 & 79,3 \\
Total & 135 & 100 \\
\hline
\end{tabular}

Tabel 7 menunjukkan kejadian DKAK berdasarkan jenis kelamin. Dari 28 responden yang mengalami DKAK, terdapat 17 responden dengan jenis kelamin perempuan $(60,7 \%)$ yang mengalami DKAK dan 11 responden dengan jenis kelamin laki-laki $(39,3 \%)$ yang mengalami DKAK.

Tabel 7. Distribusi kejadian DKAK berdasarkan jenis kelamin

\begin{tabular}{ccc}
\hline \multirow{2}{*}{ Jenis kelamin } & \multicolumn{2}{c}{ DKAK } \\
\cline { 2 - 3 } & Frekuensi & $\mathbf{( \% )}$ \\
\hline Laki-laki & 11 & 39,3 \\
Perempuan & 17 & 60,7 \\
Total & 28 & 100 \\
\hline
\end{tabular}

Tabel 8 menunjukkan kejadian DKAK pada cleaning service di RSUP Prof. Dr. R. D. Kandou Manado terbanyak pada usia 3645 tahun $(39,3 \%)$ dan paling sedikit pada usia $>65$ tahun $(3,6 \%)$.

Tabel 8. Distribusi kejadian DKAK berdasarkan kelompok usia

\begin{tabular}{ccc}
\hline \multirow{2}{*}{$\begin{array}{c}\text { Kelompok usia } \\
\text { (tahun) }\end{array}$} & \multicolumn{2}{c}{ DKAK } \\
\cline { 2 - 3 } & Frekuensi & $\mathbf{( \% )}$ \\
\hline $17-25$ & 3 & 10,7 \\
$26-35$ & 5 & 17,9 \\
$36-45$ & 11 & 39,3 \\
$46-55$ & 6 & 21,4 \\
$56-65$ & 2 & 7,1 \\
$>65$ & 1 & 3,6 \\
Total & 28 & 100 \\
\hline
\end{tabular}

Tabel 9 menunjukkan distribusi kejadian DKAK berdasarkan pendidikan terakhir. Kejadian DKAK paling banyak pada tingkat pendidikan terakhir SMP $(57,1 \%)$, diikuti oleh tingkat pendidikan terakhir SMA $(25,0 \%)$, dan SD (17,9\%).

Tabel 9. Distribusi kejadian DKAK berdasarkan pendidikan terakhir

\begin{tabular}{ccc}
\hline \multirow{2}{*}{$\begin{array}{c}\text { Pendidikan } \\
\text { terakhir }\end{array}$} & Frekuensi & $\mathbf{( \% )}$ \\
\cline { 2 - 3 } & 5 & 17,9 \\
SD & 16 & 57,1 \\
SMP & 7 & 25,0 \\
SMA & 28 & 100 \\
Total &
\end{tabular}

Tabel 10 menunjukkan kejadian DKAK berdasarkan masa kerja. Didapat-kan jumlah terbanyak pada masa kerja 1-5 tahun $(46,4 \%)$ dan yang paling sedikit pada masa kerja 11-15 tahun dan >20 tahun (masingmasing $3,6 \%$ ).

Tabel 10. Distribusi kejadian DKAK berdasarkan masa kerja

\begin{tabular}{ccc}
\hline Masa kerja & \multicolumn{2}{c}{ DKAK } \\
\cline { 2 - 3 } (tahun) & Frekuensi & $\mathbf{( \% )}$ \\
\hline$<1$ & 5 & 17,9 \\
$1-5$ & 13 & 46,4 \\
$6-10$ & 6 & 21,4 \\
$11-15$ & 1 & 3,6 \\
$16-20$ & 2 & 7,1 \\
$>20$ & 1 & 3,6 \\
Total & 28 & 100 \\
\hline
\end{tabular}

Tabel 11 menunjukkan kejadian DKAK berdasarkan penggunaan APD. Terdapat 9 $(32,1 \%)$ dari 69 petugas yang menggunakan APD mengalami DKAK, dan 19 (67,9\%) dari 66 petugas yang tidak menggunakan APD mengalami DKAK.

Tabel 11. Distribusi kejadian DKAK berdasarkan penggunaan APD

\begin{tabular}{ccc}
\hline \multirow{2}{*}{ Penggunaan APD } & \multicolumn{2}{c}{ DKAK } \\
\cline { 2 - 3 } & Frekuensi & $\mathbf{( \% )}$ \\
\hline Menggunakan & 9 & 32,1 \\
Tidak menggunakan & 19 & 67,9 \\
Total & 28 & 100 \\
\hline
\end{tabular}




\section{BAHASAN}

Berdasarkan hasil penelitian yang dilakukan pada petugas cleaning service di RSUP Prof. Dr. R. D. Kandou Manado terdapat $28(20,7 \%)$ dari 135 responden yang mengalami DKAK. Diagnosis DKAK dilakukan dengan menggunakan kriteria Mathias dan juga melalui pemeriksaan dokter spesialis. Hasil penelitian ini sejalan dengan penelitian yang dilakukan oleh Elston et al. ${ }^{13}$ yang menunjukkan $9-35 \%$ penyakit kulit akibat kerja merupakan DKAK khususnya pada area tangan dan lengan.

Petugas cleaning service di RSUP Prof R. D. Kandou Manado yang mengalami DKAK memiliki keluhan seperti rasa gatal, rasa terbakar, nyeri, kulit kemerahan, bengkak, bintik berair, lepuhan dan kerusakan kuku. Keluhan dialami setelah terpajan cairan pembersih, sarung tangan, dan atau alat pembersih beberapa menit setelah pajanan hingga setelah terjadi pajanan berulang. Hal tersebut terjadi akibat proses kerja yang mengharuskan petugas cleaning service berkontak dengan bahanbahan kimia penyebab DKAK.

Berdasarkan jenis kelamin, kejadian DKAK pada petugas cleaning service di RSUP Prof. Dr. R. D. Kandou Manado terbanyak pada jenis kelamin perempuan yaitu 17 responden $(60,7 \%)$ sedangkan pada jenis kelamin laki-laki 11 responden $(39,3 \%)$. Hal ini sejalan dengan penelitian yang dilakukan pada petugas kesehatan di Rumah Sakit Tanjung, Tabalong, Kalimantan Selatan yaitu dari 16 responden yang menderita DKAK, terdapat 15 responden yang berjenis kelamin perempuan, dan 1 responden berjenis kelamin laki-laki. ${ }^{14}$

Berdasarkan pengamatan pada lokasi penellitian, petugas perempuan lebih banyak melakukan kontak dengan bahanbahan alergen dan iritan yang ada di lingkungan pekerjaan sehingga petugas perempuan lebih mudah terkena DKAK. Selain itu terdapat perbedaan antara kulit pria dengan wanita, perbedaan tersebut dilihat dari jumlah folikel rambut, kelenjar sebasea dan hormon. Hormon testosteron pada laki-laki dapat menyebabkan kulit laki- laki 20\% lebih tebal dibandingkan perempuan. Ketebalan kulit memengaruhi ketahanan kulit terhadap paparan bahan kimia. Selain itu, laki-laki mempunyai kelenjar sebasea yang lebih aktif daripada perempuan dan produksi sebum dua kali lebih banyak dari perempuan, sehingga pada perempuan kulit akan lebih kering dibandingkan laki-laki. Terlebih lagi seiring dengan bertambahnya usia, maka perempuan berisiko lebih besar terkena DKAK dibandingkan laki-laki. ${ }^{2}$

Berdasarkan usia, kejadian DKAK pada petugas cleaning service di RSUP Prof. Dr. R. D. Kandou Manado terbanyak pada kelompok usia 36-45 tahun yaitu 11 (39,3\%) dari total 28 responden yang menderita DKAK. Hasil penelitian ini sejalan dengan penelitian Kusworo ${ }^{15}$ yaitu kejadian DKAK didominasi kelompok umur 31-40 tahun sebanyak 24 dari 60 responden. Hasil penelitian ini tidak selaras dengan penelitian oleh Afifah ${ }^{16}$ yang mendapatkan kejadian DKAK terbanyak pada usia $<30$ tahun yaitu $17(67,7 \%)$ dari 28 responden. Faktor individu turut berpe-ngaruh pada kejadian DKAK, misalnya perbedaan ketebalan kulit menyebabkan perbedaan permeabilitas. Pada usia anak di bawah 8 tahun dan usia lanjut lebih mudah teriritasi sehingga lebih rentan terhadap DKAK. ${ }^{3}$ Perubahan struktur kulit seiring dengan pertambahan usia namun tetap melakukan pekerjaan yang berhubungan dengan bahan-bahan alergen maupun iritan yang ada di lingkungan pekerjaan dapat menjadi salah satu faktor risiko DKAK. DKAK tidak hanya muncul pada usia tertentu namun dapat mengenai segala usia dan meningkat pada usia yang produktif. $^{17}$

Berdasarkan pendidikan terakhir, kejadian DKAK pada petugas cleaning service di RSUP Prof. Dr. R. D. Kandou Manado terbanyak pada petugas dengan pendidikan terakhir SMP yaitu 16 responden $(57,1 \%)$. Tingkat pendidikan dapat berhubungan dengan perilaku kesehatan kerja di lingkungan kerja, seperti kesadaran untuk membersihkan diri pada saat selesai melakukan pekerjaan dan juga penggunaan APD sehingga dapat mengurangi potensi 
bahan-bahan iritan dan alergen penyebab DKAK menempel pada kulit untuk waktu yang lama, dan hal ini dapat mencegah terjadinya DKAK. ${ }^{15,18}$

Berdasarkan masa kerja, kejadian DKAK pada petugas cleaning service di RSUP Prof. Dr. R. D. Kandou Manado terbanyak pada responden dengan masa kerja 1-5 tahun yaitu 13 responden $(46,4 \%)$. DKAK dapat terjadi pada petugas cleaning service dengan masa kerja yang baru maupun masa kerja yang lama akibat kontak dengan bahan-bahan penyebab DKAK. Kelainan dapat timbul segera setelah kontak, beberapa hari, minggu, bulan, bahkan tahun ataupun setelah terjadi pajanan berulang. ${ }^{4}$ Berdasarkan penelitian yang dilakukan pada petugas cleaning service di Kampus UIN Jakarta menunjukkan tidak ada hubungan antara masa kerja dengan kejadian DKAK. ${ }^{18}$ Demikian juga dengan penelitian yang dilakukan pada cleaning service di Rumah Sakit Umum Abdul Moeloek, bahwa tidak terdapat hubungan antara masa kerja dengan kejadian DKAK. Terdapat $47(46,1 \%)$ dari 102 responden yang mengalami DKAK dengan masa kerja yang bervariasi. ${ }^{11}$

Masa kerja yang baru ataupun lama tetap mempunyai risiko mengalami DKAK. Kejadian DKAK dapat dipengaruhi beberapa faktor seperti riwayat atopi, frekuensi kontak, lama kontak, jenis pekerjaan, lokasi kerja, serta jenis bahan kimia. ${ }^{3,4}$ Pada penelitian ini ditemukan perbedaan pada lokasi kerja pada masing-masing responden, misalnya ada responden yang bekerja di ruangan, rawat inap, rawat jalan, laboratorium, halaman dan taman sehingga terdapat perbedaan lama kontak dan frekuensi kontak dengan bahan-bahan penyebab DKAK seperti cairan pembersih lantai, cairan pembersih kaca, detergen, dan bahan kimia lainnya. Responden yang bekerja di ruangan lebih sering terpapar dengan bahan-bahan kimia ini dibandingkan dengan responden yang ditugaskan di halaman dan taman. DKAK dapat terjadi pada semua individu jika terjadi kontak yang memadai dengan bahan-bahan penyebab DKAK. ${ }^{11}$
Berdasarkan penggunaan APD, kejadian DKAK pada petugas cleaning service di RSUP Prof. Dr. R. D. Kandou Manado terbanyak pada responden yang tidak menggunakan APD pada saat bekerja yaitu $19(67,9 \%)$ dari 28 responden yang mengalami DKAK. Hasil penelitian yang dilakukan pada petugas cleaning service di Rumah Sakit Umum Abdul Moeloek menunjukkan bahwa petugas yang tidak menggunakan APD 2,71 kali lebih berisiko mengalami DKAK bila dibandingkan dengan petugas yang menggunakan APD. ${ }^{11}$ Berdasarkan penelitian yang telah dilaku-kan, didapatkan bahwa responden yang tidak menggunakan APD disebabkan oleh karena kurangnya pengetahuan mengenai jenis APD yang sesuai, manfaat pengguna-an APD, ada pula yang lupa memakai APD, serta kurangnya ketersediaan APD, Beberapa responden juga mengatakan bahwa kurang leluasa melakukan pekerjaan bila menggunakan APD. Para pekerja tidak mengetahui jika kontak langsung dengan bahan kimia selama melakukan pekerjaan dapat mengakibatkan penyakit kulit akibat kerja salah satunya DKAK. Ditemukan pula responden yang mengalami DKAK meskipun menggunakan APD pada saat bekerja. Hal ini dapat terjadi oleh karena kondisi kulit tidak sesuai dengan jenis APD yang digunakan karena mengandung bahanbahan yang dapat menyebabkan reaksi alergi maupun iritasi pada kulit. Sarung tangan lateks dan sarung tangan dengan bedak dapat menyebabkan reaksi alergi. Reaksi dapat terjadi secara cepat ataupun setelah pemakaian yang lebih lama. ${ }^{11}$

\section{SIMPULAN}

Dari hasil penelitian yang dilakukan pada petugas cleaning service di RSUP Prof. Dr. R. D. Kandou Manado dapat disimpulkan bahwa dermatitis kontak akibat kerja ditemukan sekitar $20 \%$.

\section{DAFTAR PUSTAKA}

1. Peraturan Menteri Kesehatan Republik Indonesia Nomor 56 Tahun 2016. Penyelenggaraan pelayanan kesehatan akibat kerja. Jakarta: Peraturan Menteri 
Kesehatan RI, 2016.

2. Honari G, Taylor JS, Sood A. Occupational skin diseases due to irritants and allergens. In: Goldsmith LA, Katz SI, Gilchrest BA, Paller AS, Leffell DJ, Wolff K, editors. Fitzpatrick's Dermatology in General Medicine (7th ed). New York: McGraw-Hill, 2012; p. 2612-18.

3. Sularsito SA, Soebaryo RW. Dermatitis kontak. In: Buku Ajar Ilmu Penyakit Kulit dan Kelamin (7th ed). Jakarta: Fakultas Kedokteran Universitas Indonesia, 2015; p. 157-65.

4. Behroozy A, Keegel TG. Wet-work exposure: a main risk factor for occupational hand dermatitis. Saf Health Work. 2014;5(4): 175-80.

5. James WD. Berger T, Elston DM, editors. Andrew's Diseases of the Skin: Clinical Dermatology (12th ed). Chapter 6, sub topic: ocupational contact dermatitis. Cina: Saunders Elesevier, 2012; p. 109

6. Nanto SS. Kejadian timbunya dermatitis kontak pada petugas kebersihan. Majority. 2015;4(8):147-51.

7. Cahil J, Williams JDL, Matheson MC, Palmer AM, Burgess JA, Dharmage SC, et al. Occupational contact dermatitis: a review of 18 years of data from an occupational dermatology clinic in Australia. Victoria: Safe Work Australia, 2012.

8. Balgis V, Retno S, Indrastuti N, Soebono H. Laporan kasus dermatitis kontak akibat kerja pada pekerjs kebun anggrek. Maj Ilm Dermato-Venerologica Indones, 2009;36(4):163.

9. Wu B. Skin problems in professional cleaners [MD candidate]. Keck School of Medicine. A manuscript in DermNet New Zealand. December 2015. [cited 2017 Aug 7]. Available from: https://www.dermnetnz.org/topics/skinproblems-in-professional-cleaners/

10. Douwes J, Slater T, McLean D, Pearce N, Judd L, Firestone R, etc. Occupational dermatitis in New Zealand cleaners. Centre for Public Health Reasearch, Massey University. Study report for the Department of Labour. 2014:1-97.
11. Saftarina F, Sibero HT, Aditya M, Dinanti BR. Prevalensi dermatitis kontak akibat kerja dan faktor yang mempengaruhinya pada pekerja cleaning service di Rumah Sakit Umum Abdul Moeloek. Bandar Lampung: Prosiding Seminar Presentasi Artikel Ilmiah Dies Natalis FK Unila ke 13, 2015 Okt; p. 19-25.

12. Lau MYZ, Burgess JA, Nixon R, Dharmage SC, Matheson MC. A review of the impact of occupational contact dermatitis on quality of life. Journal of Allergy. Vol. 2011(2011): 1-12.

13. Elston DM, Ahmed DDF, Watsky KL, Schwarzenberger K. Hand dermatitis. August 2002. [cited 2017 Nov 17]. Available from: http://www.jaad.org/ article/.S0190-9622(02)000610/fulltext

14. Anshar R, Pramuningtyas R, Udiana D. Hubungan pekerja basah dengan kejadian dermatitis kontak akibat kerja pada petugas kesehatan di Rumah Sakit $\mathrm{X}$ Tanjung, Tabalong, Kalimantan Selatan. Biomedika. 2016;8:28.

15. Kusworo NSR. Hubungan antara lama kontak dengan kejadian dermatitis kontak akibat kerja pada pekerja bengkel kendaraan bermotor di Kecamatan Kartasura [Skripsi]. Surakarta: Fakultas Kedokteran Universitas Muhammadiyah Surakarta; 2015.

16. Afifah A. Faktor-faktor yang berhubungan dengan terjadinya dermatitis kontak akibat kerja pada karyawan binatu [Skripsi]. Semarang: Fakultas Kedokteran Universitas Diponegoro; 2012.

17. Sunaryo Y. Pandaleke HEJ, Kapantow MG. Profil dermatitis kontak di poliklinik kulit dan kelamin BLU RSUP Prof. Dr. R. D. Kandou Manado periode Januari-Desember 2012. e-Clinic. 2014;2:6.

18. Septian S. Faktor-faktor yang berhubungan dengan kejadian dermatitis kontak akibat kerja pada cleaning service di Kampus UIN Syarif Hidayatullah Jakarta [Skripsi]. Jakarta: Fakultas Kedokteran dan Ilmu Kesehatan UIN Syarif Hidayatullah; 2012. 